\title{
Reduction of Current Ripples due to Current Measurement Errors in a Doubly Fed Induction Generator
}

\author{
Gwi-Geun Park*, Seon-Hwan Hwang ${ }^{* *}$, Jang-Mok Kim ${ }^{\dagger}$, Kyo-Beum Lee***, and Dong-Choon Lee ${ }^{\ddagger}$ \\ * AC Control 2 Group, AC Control R\&D Lab, LG Electronics Inc., Changwon, Korea \\ $\dagger * *$ School of Electrical Eng., Pusan National University, Busan, Korea \\ *** Division of Electrical and Computer Eng., Ajou University, Suwon, Korea \\ $\ddagger$ Dept. of Electrical Eng., Yeungnam University, Gyeongsan, Korea
}

\begin{abstract}
This paper proposes a new compensation algorithm for the current measurement errors in a DFIG (Doubly Fed Induction Generator). Generally, current measurement path with current sensors and analog devices has non-ideal factors like offset and scaling errors. As a result, the $d q$-axis currents of the synchronous reference frame have one and two times ripple components of the slip frequency. In this paper, the main concept of the proposed algorithm is implemented by integrating the 3-phase rotor currents into the stationary reference frame to compensate for the measured current ripples in a DFIG. The proposed algorithm has several beneficial features: easy implementation, less computation time, and robustness with regard to variations in the electrical parameters. The effectiveness of the proposed algorithm is verified by several experiments.
\end{abstract}

Key Words: Current measurement errors, Current ripples, DFIG, Offset error, Scaling error

\section{INTRODUCTION}

A doubly fed induction generator (DFIG) [1]-[11] is a competitive choice in the wind power industry for allowing the direct connection of a stator to the AC grid under variable rotor speeds as well as for providing active and reactive power control. Depending on the required speed range, the rotor converter rating is usually small compared to the machine rating. Therefore, a DFIG is ideal for applications such as wind, pumped storage, and micro-hydro power plants which inherently favor variable speed operation. A rotor-side converter provides the fundamental voltage of the slip frequency to the rotor side. Vector control of the rotor current is introduced in order to effectively control the active and reactive power in the output terminal of a DFIG. Therefore, precise measurement of the rotor current is very important [1]-[5].

The rotor-side and grid-side currents are measured through current sensors, low pass filters, and analog-to-digital (A/D) converters. Current measurement errors are generated due to the non-linearity of the current sensors, quantization error of the A/D converters, and the thermal drift of the analog devices [12], [13]. These errors deteriorate the control performance

\footnotetext{
Manuscript received Feb. 12, 2010; revised Apr. 5, 2010

$\dagger$ Corresponding Author: jmok@pusan.ac.kr

Tel: +82-51-510-2366, Fax: +82-51-513-0212, Pusan Nat'l University

* AC Control 2 Group, AC Control R\&D Lab, LG Elec. Inc., Korea

** School of Electrical Eng., Pusan Nat'l University, Korea

*** Division of Electrical and Computer Eng., Ajou University, Korea

$\ddagger$ Dept. of electrical Eng., Yeungnam University, Korea
}

of a DFIG. In addition, there is increasing concern about the rotor-side harmonics in DFIGs. Previous researchers have studied the harmonics transfer from the rotor-side to the gridside of generators [9]-[11].

This paper proposes a new algorithm to compensate for the current measurement errors in DFIG operation except for the commissioning or startup procedure. It is easily implemented by integrating the 3 -phase rotor currents into the stationary reference frame without the calculation of complex equations like FFT and $d q$ transformation to change from 3-phase rotor currents to the $d q$-axis currents of the synchronous reference frame. Therefore, it requires less computation time and low a performance DSP for implementation. The usefulness of the proposed algorithm is verified by several experiments.

\section{Description OF A DFIG [1]-[11]}

The configuration of a DFIG system is shown in Fig. 1. As shown in Fig. 1, the vector control strategy of a DFIG system is based on stator flux oriented control. Since a stator is connected to the grid, the stator magnetizing current can be considered constant. For vector control of a DFIG, the stator fluxes in a stationary reference frame can be calculated as follows:

$$
\begin{aligned}
& \lambda_{d s s}=\int\left(V_{d s s}-R_{s} i_{d s s}\right) d t \\
& \lambda_{q s s}=\int\left(V_{q s s}-R_{s} i_{q s s}\right) d t .
\end{aligned}
$$




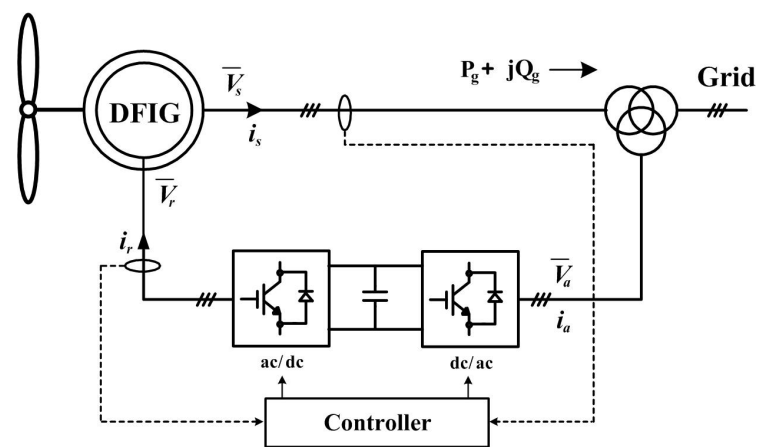

Fig. 1. Basic configuration of DFIG wind turbine.

The amplitude of the stator flux and the instantaneous location of the stator's rotating magnetic field are given by:

$$
\begin{aligned}
& \left|\lambda_{s}\right|=\sqrt{\lambda_{d s s}^{2}+\lambda_{q s s}^{2}} \\
& \theta_{s}=\tan ^{-1} \frac{\lambda_{q s s}}{\lambda_{d s s}} .
\end{aligned}
$$

In a synchronous reference frame, the $d$-axis flux is a constant and the $q$-axis flux is zero. Therefore, the voltage equations and stator flux are given as follows:

$$
\begin{aligned}
& v_{d s e}=R_{s} i_{d s e}+\frac{d \lambda_{d s e}}{d t} \cong 0 \\
& v_{q s e}=R_{s} i_{\text {qse }}+\omega_{e} \lambda_{d s e} \\
& \lambda_{d s e}=L_{s} i_{d s e}+L_{m} i_{d r e} \\
& \lambda_{q s e}=L_{s} i_{q s e}+L_{m} i_{\text {qre }} \cong 0 .
\end{aligned}
$$

Active and reactive powers at the stator-side can be expressed by (9), and (10), respectively.

$$
\begin{aligned}
P_{s} & =\frac{3}{2}\left(v_{q s e} i_{q s e}+v_{d s e} i_{d s e}\right) \\
Q_{s} & =\frac{3}{2}\left(v_{q s e} i_{d s e}-v_{d s e} i_{q s e}\right) .
\end{aligned}
$$

By using (5), (6), (7), and (8), (9) and (10) can be rewritten as follows:

$$
\begin{aligned}
P_{s} & =\frac{3}{2}\left[v_{q s e}\left(-\frac{L_{m}}{L_{s}}\right)\right] i_{\text {qre }} \\
Q_{s} & =\frac{3}{2} \omega_{e} \lambda_{d s e}\left(\frac{\lambda_{d s e}-L_{m} i_{d r e}}{L_{s}}\right) .
\end{aligned}
$$

\section{Analysis of CURRent Measurement ERrors} [12], [13]

\section{A. Offset errors}

In a DFIG, the path of the current measurement for vector control is shown in Fig. 2. Rotor currents are transduced to the voltage signal by current sensors and transformed into digital values via low-pass filters and $\mathrm{A} / \mathrm{D}$ converters.

Due to the unbalanced positive and negative supply voltage of a current sensor and the nonideal analog devices in the current measurement path, dc offset is an inevitable problem.

The dc offset can be included in the measured real phase currents. Therefore, the 3-phase rotor currents are calculated

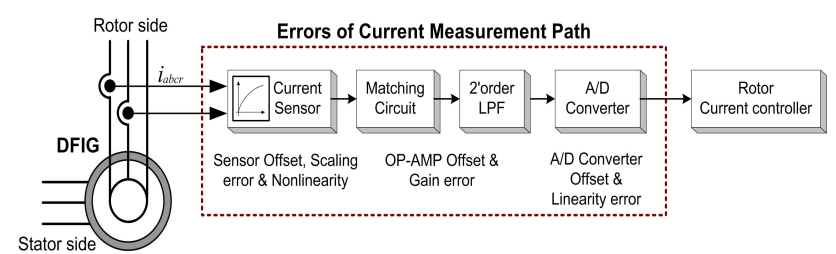

Fig. 2. Path of current measurement in DFIG.

as:

$$
\begin{aligned}
& i_{a r_{-} s e n s}=i_{a r}+\Delta I_{a r} \\
& i_{b r_{-} s e n s}=i_{b r}+\Delta I_{b r} \\
& i_{c r \_s e n s}=-\left(i_{a r_{\_} s e n s}+i_{b r \_s e n s}\right)
\end{aligned}
$$

where, $\Delta I_{a r}$, and $\Delta I_{b r}$ are the offset errors of the $a$-phase and $b$-phase currents, respectively. $i_{a r_{-} s e n s}, i_{b r_{-} s e n s}$, and $i_{c r_{-} s e n s}$ are the measured 3-phase rotor currents. $i_{a r}, i_{b r}$, and $i_{c r}$ are the ideal rotor currents.

The $d q$-axis currents of the synchronous reference frame applied to (13), (14), and (15) can be expressed as:

$$
\begin{aligned}
& i_{d r e_{-} s e n s}^{s l}=i_{d r e}^{s l}+\Delta I_{d r e}^{s l} \\
& \Delta I_{d r e}^{s l}=\Delta I_{a r} \cos \theta_{s l}+\frac{1}{\sqrt{3}}\left(\Delta I_{a r}+2 \Delta I_{b r}\right) \sin \theta_{s l} \\
& i_{q r e_{-} s e n s}^{s l}=i_{q r e}^{s l}+\Delta I_{q r e}^{s l} \\
& \Delta I_{q r e}^{s l}=-\Delta I_{a r} \sin \theta_{s l}+\frac{1}{\sqrt{3}}\left(\Delta I_{a r}+2 \Delta I_{b r}\right) \cos \theta_{s l}
\end{aligned}
$$

where, $\Delta I_{d r e}^{s l}$ and $\Delta I_{q r e}^{s l}$ are the offset errors in the $d q$-axis currents of the synchronous reference frame.

The $d q$-axis currents of the synchronous reference frame due to the offset errors can be derived as shown in (17) and (19). As a result, the synchronous $d q$-axis currents have the fundamental ripple components of the slip frequency.

\section{B. Scaling errors}

Scaling errors may be generated by the non-linearity of the current sensor itself, the OP-amp circuit between the current sensors and A/D input, and the non-linearity of the $A / D$ converters. If the rotor currents contain scaling errors, they can be expressed as (20) and (21).

$$
\begin{aligned}
& i_{a r \_s e n s}=-K_{a} I \sin \theta_{s l} \\
& i_{b r \_s e n s}=-K_{b} I \sin \left(\theta_{s l}-\frac{2}{3} \pi\right)
\end{aligned}
$$

where, $K_{a}$ and $K_{b}$ denote the scaling errors of the $a$-phase and $b$-phase currents, respectively. $\theta_{s l}$ represents the rotor slip angle.

From (20) and (21), the scaling error components of the measured synchronous $d$-axis and $q$-axis currents can be represented as:

$$
\begin{aligned}
& \Delta I_{d r e \_s c a l e}^{s l}=i_{d r e \_s e n s}^{s l}-i_{d r e}^{s l} \\
& =\frac{\left(K_{b}-K_{a}\right)}{\sqrt{3}} I \sin \left(2 \theta_{s l}-\frac{\pi}{6}\right)+\frac{\left(K_{b}-K_{a}\right)}{2 \sqrt{3}} I \\
& \Delta I_{q r e \_s c a l e}^{s l}=i_{q r e_{-} s e n s}^{s l}-i_{q r e}^{s l} \\
& =\frac{\left(K_{b}-K_{a}\right)}{\sqrt{3}} I \sin \left(2 \theta_{s l}+\frac{\pi}{3}\right)+\frac{\left(K_{b}-K_{a}\right)}{2} I
\end{aligned}
$$


where, $\Delta I_{d r e \_s c a l e}^{s l}$ and $\Delta I_{q r e \_s c a l e}^{s l}$ are the ripple components of the $d$-axis and $q$-axis due to the scaling errors, respectively.

As shown in (22) and (23), these terms have two times $\left(2 \theta_{s l}\right)$ ripple components of the fundamental slip frequency. At the stator side, the effect of the offset and scaling errors on the active and reactive powers can be expressed as follows:

$$
\begin{aligned}
\Delta P_{s}= & -\frac{3}{2} \frac{L_{m}}{L_{s}} v_{q s e}\left[-\Delta I_{a r} \sin \theta_{s l}+\frac{1}{\sqrt{3}}\left(2 \Delta I_{b r}+\Delta I_{a r}\right) \cos \theta_{s l}\right] \\
& -\frac{3}{2} \frac{L_{m}}{L_{s}} v_{q s e}\left[\frac{\left(K_{b}-K_{a}\right)}{\sqrt{3}} I \sin \left(2 \theta_{s l}+\frac{1}{3} \pi\right)\right] \\
\Delta Q_{s}= & -\frac{3}{2} \frac{L_{m}}{L_{s}} \omega_{e} \lambda_{d s e}\left[\Delta I_{a r} \cos \theta_{s l}+\frac{1}{\sqrt{3}}\left(2 \Delta I_{b r}+\Delta I_{a r}\right) \sin \theta_{s l}\right] \\
& -\frac{3}{2} \frac{L_{m}}{L_{s}} \omega_{e} \lambda_{d s e}\left[\frac{\left(K_{b}-K_{a}\right)}{\sqrt{3}} I \sin \left(2 \theta_{s l}-\frac{1}{6} \pi\right)\right] .
\end{aligned}
$$

From (24) and (25), the offset and scaling errors at the rotor side cause one and two times ripple components of the slip frequency on the active and reactive powers.

\section{Proposed Compensation Algorithm}

\section{A. Compensation of offset errors}

Integrations of the $a$-phase and $b$-phase currents from 0 to $2 \pi$ are calculated to derive the offset errors as shown in (26) and (27):

$$
\begin{aligned}
& \sec 1=\int_{0}^{2 \pi} i_{a r_{-} s e n s} d \theta_{s l}=2 \pi \Delta I_{a r} \\
& \sec 2=\int_{0}^{2 \pi} i_{b r \_s e n s} d \theta_{s l}=2 \pi \Delta I_{b r} .
\end{aligned}
$$

By integrating the $a$-phase and $b$-phase currents, the sinusoidal terms of $-K_{a} I \sin \theta_{s l}$ and $-K_{b} I \sin \left(\theta_{s l}-\frac{2}{3} \pi\right)$ can be removed from (26) and (27). The rotor position must be synchronized with the rotor current to get the offset constants, $\Delta I_{a r}$, and $\Delta I_{b r}$ from the measured rotor currents.

Fig. 3 shows the concept of getting the offset errors by using (26) and (27). As a result, the offset error components are easily obtained as shown in (26) and (27).

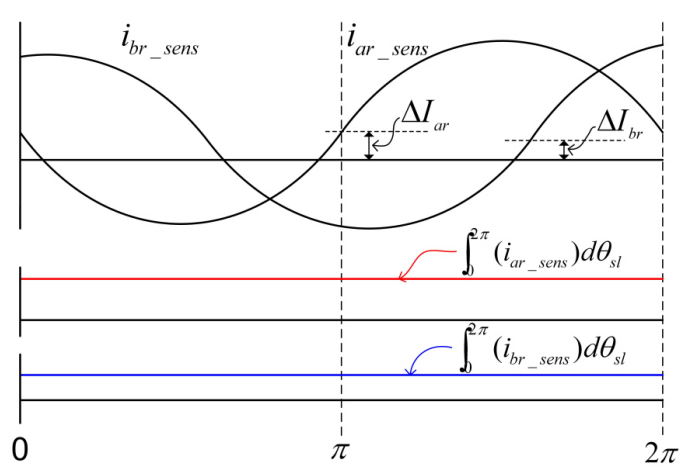

Fig. 3. Detection of offset errors. (a) 3-phase currents including offset errors. (b) integration results of $a$-phase rotor current. (c) integration results of $b$-phase rotor current.

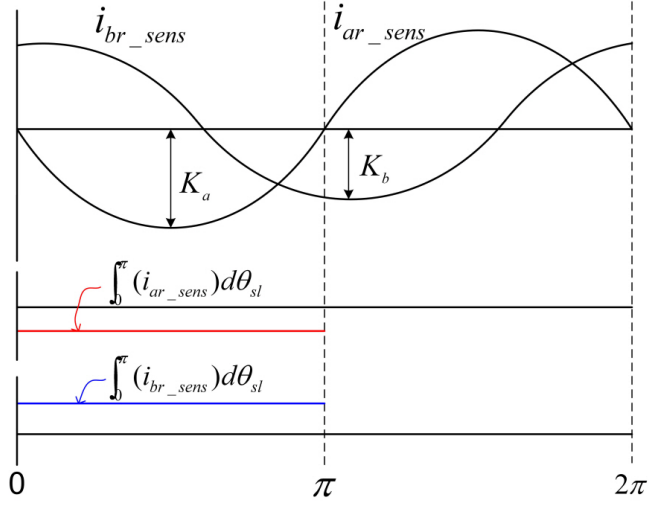

Fig. 4. Detection of scaling errors. (a) 3-phase currents including scaling errors. (b) integration results of $a$-phase rotor current. (c) integration results of $b$-phase rotor current.

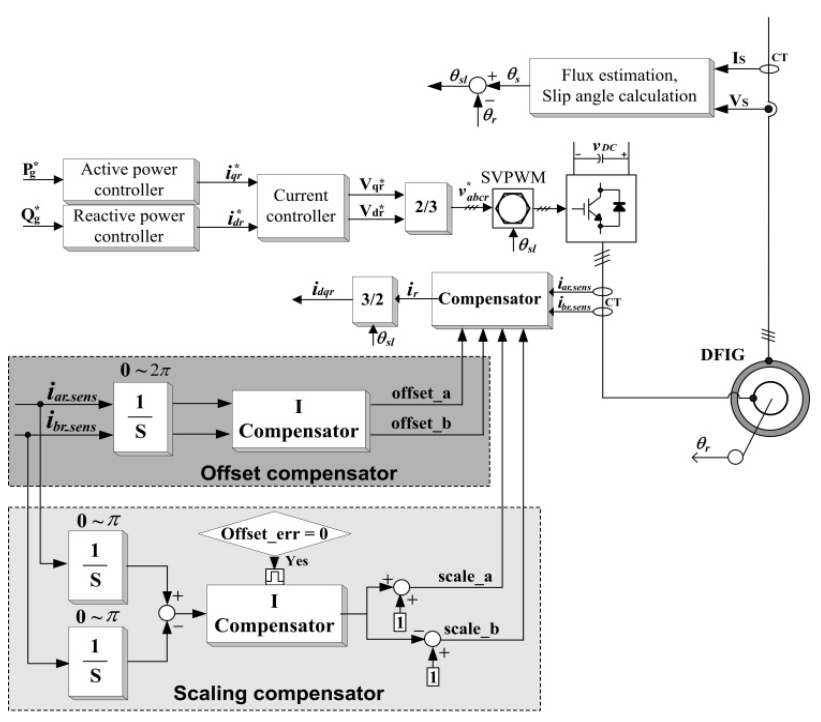

Fig. 5. Block diagram of the proposed algorithm.

\section{B. Compensation of scaling errors}

From (20) and (21), the scaling errors can be derived by integrating the $a$-phase and $b$-phase currents from 0 to $\pi$ into the stationary reference frame as shown in (28) and (29), respectively.

$$
\begin{aligned}
\sec I & =\int_{0}^{\pi} i_{a r_{-} \text {sens }} d \theta_{s l}=\int_{0}^{\pi}\left(-K_{a} I \sin \theta_{s l}\right) d \theta_{s l} \\
& =-2 K_{a} I \\
\sec I I & =\int_{0}^{\pi} i_{b r_{-} \text {sens }} d \theta_{s l}=\int_{0}^{\pi}\left(-K_{b} I \sin \left(\theta_{s l}-\frac{2}{3} \pi\right)\right) d \theta_{s l} \\
& =K_{b} I \\
\varepsilon_{\text {scale }} & =\left(\frac{\sec I}{2}+\sec I I\right)=-\left(K_{a}-K_{b}\right) I .
\end{aligned}
$$

The rotor position must be synchronized with the rotor current to get the difference in the scaling error constants, $\left(K_{a}-K_{b}\right)$.

Fig. 4 shows the concept of acquiring the differences of the scaling errors by using (28), (29), and (30). 


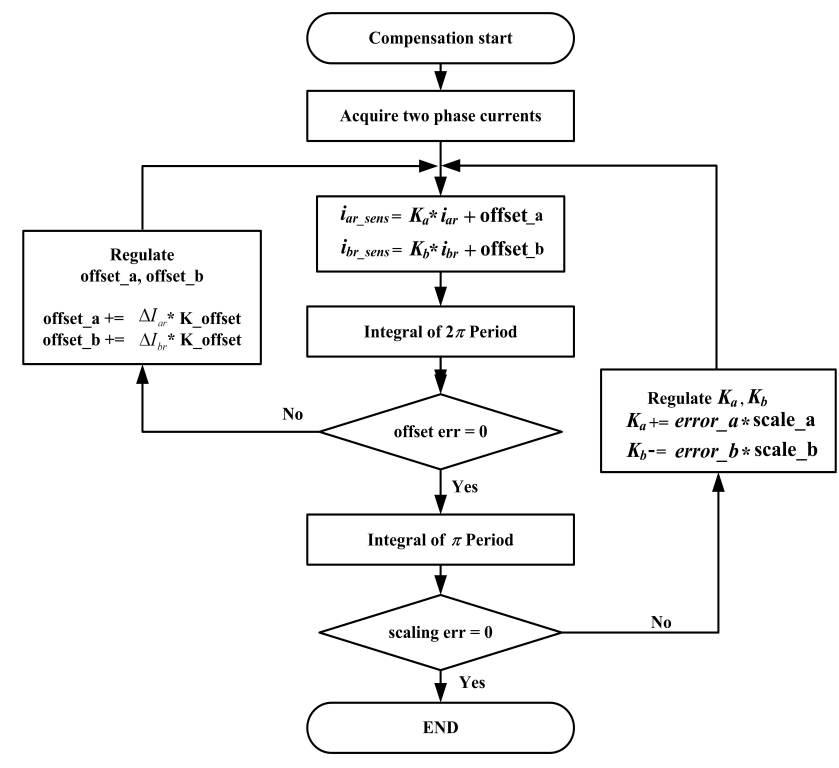

Fig. 6. Flow chart of the proposed algorithm.

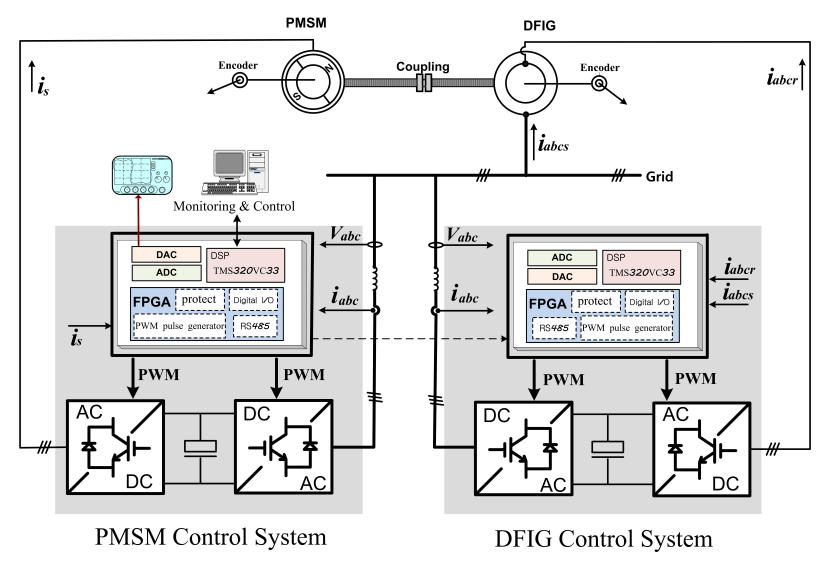

Fig. 7. Block diagram of experimental setup.

\section{Implementation compensation of the offset and scaling errors}

The main control block diagram of the proposed method is shown in Fig. 5. It consists of two parts that are two shaded rectangularity. (26), (27), (28), and (29) are used to remove the current ripple caused by the offset and scaling errors. As shown in Fig. 5, the proposed compensation algorithm is easily implemented just by integrating the $a$-phase and $b$-phase currents into the stationary reference frame. Therefore, little computation time is required to compensate for the current measurement errors when compared to the conventional algorithms [12], [13].

Fig. 6 shows a flow chart of the proposed algorithm to explain the concept of the proposed compensation algorithm as shown in the shaded parts of Fig. 5.

\section{EXPERIMENTAL RESULTS}

Fig. 7 shows a whole block diagram of the DFIG used in the experiments. Fig. 8 shows a photograph of a wind power system using a DFIG. This system consists of the prime motor for the operation of the wind turbine, the induction generator

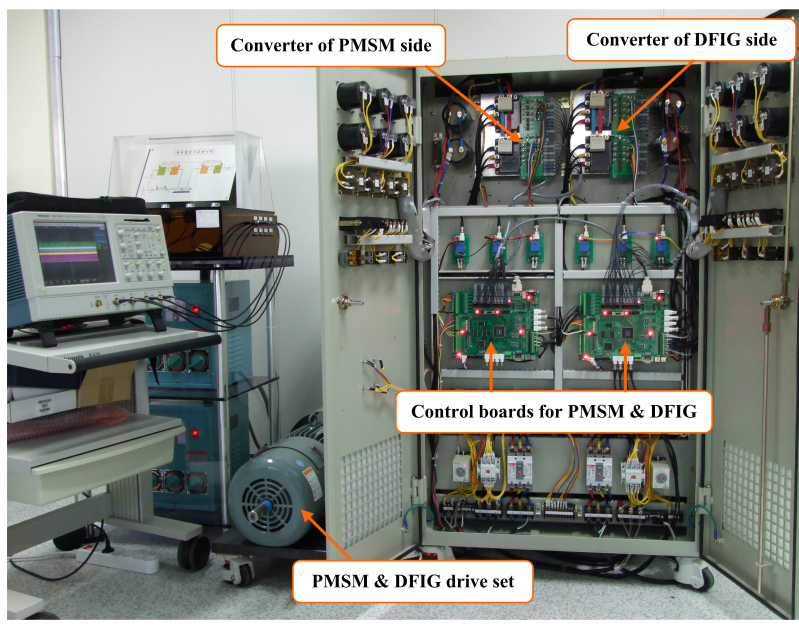

Fig. 8. Photograph of the wind power system using DFIG.

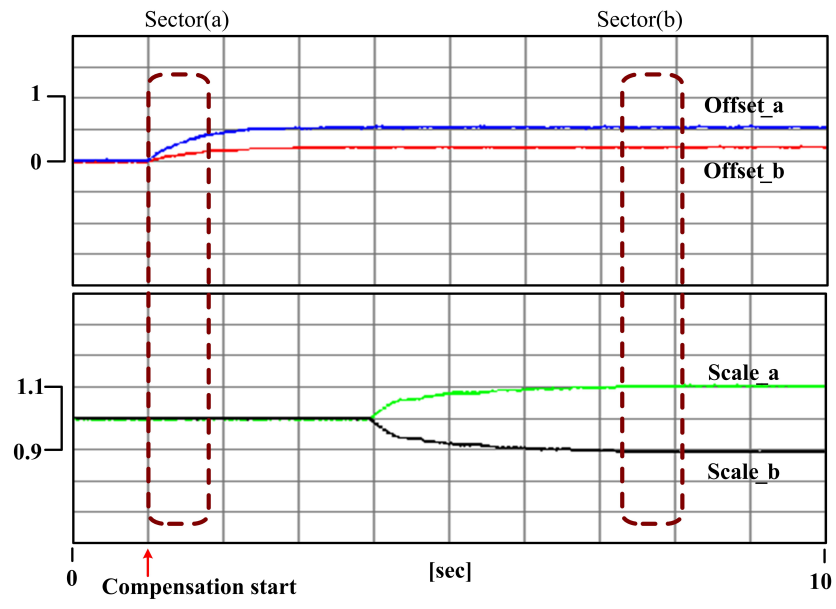

Fig. 9. Characteristics of compensation operation.

of the wound rotor, and the cubicle of the control system including the DSP control boards for the PWM inverter and the PWM converters. The parameters of the implemented DFIG system are shown in the Appendix. Experimental results will help evaluate the feasibility of the proposed algorithm in real situations. The offset and scaling errors are given as $\Delta I_{a r}$ $=0.5[\mathrm{~A}], \Delta I_{b r}=0.2[\mathrm{~A}], K_{a}=1.1$ and $K_{b}=0.9$ for the experiment.

Fig. 9 shows the process steps of the compensation due to the current measurement errors. The compensation starts at 1 [sec], and the offset errors track the real value as shown in sector (a) of Fig. 9. The scaling compensation starts at about 4 [sec], and the scaling errors are tracked in sector (b) of Fig. 9.

Fig. 10 shows the experimental $d q$-axis rotor current waveforms in the synchronous reference frame without the compensation for the current measurement errors. This figure shows $d q$-axis current ripples of one and two times fundamental slip frequency due to the offset and scaling errors, respectively. Six times the fundamental slip frequency is caused by the dead time of the inverter [14], [15]. The compensation of dead time is beyond the scope of this paper.

The compensation effects of the proposed algorithm are shown in Fig. 11. The current ripples are decreased more 


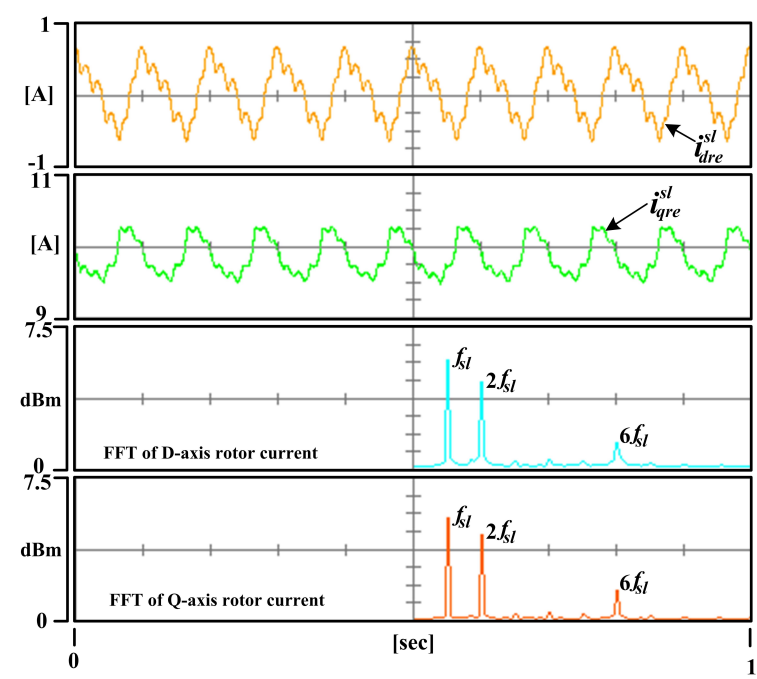

Fig. 10. $d q$-axis currents in the synchronous reference frame and FFT results without the compensation.

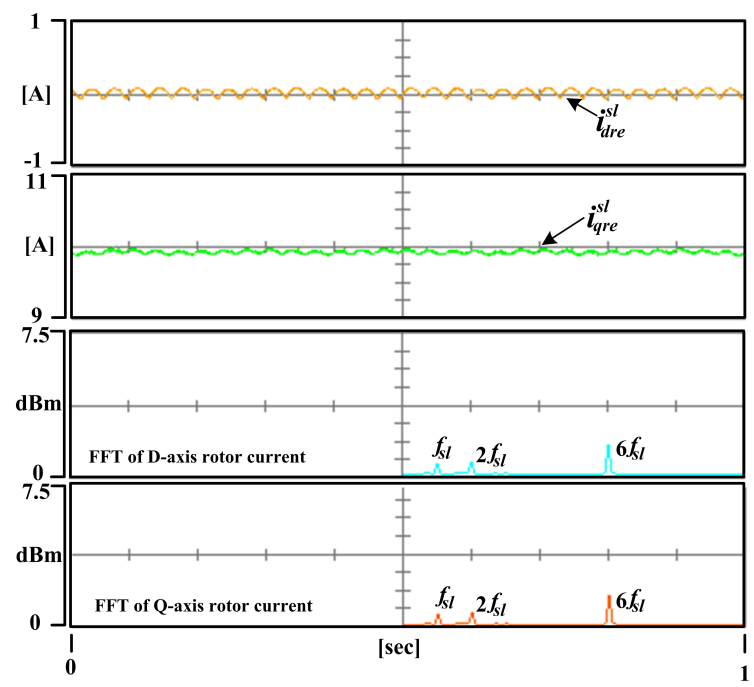

Fig. 11. $d q$-axis currents in the synchronous reference frame and FFT results with the compensation.

clearly via the FFT results. Unlike Fig. 10, the ripple components of the $d q$-axis currents are nearly removed.

Figs. 12 and 13 show the process of the compensation as described in the flow chart from Fig. 6. This compensation algorithm is implemented in the stationary reference frame for the simple calculation and implementation of the proposed method.

The experimental waveforms are the $d$-axis and $q$-axis rotor currents of the synchronous reference frame to verify the proposed compensation algorithm.

Fig. 12 shows the compensation process for the offset errors, and Fig. 13 shows that of the scaling errors.

Figs. 14, 15, and 16 show the experimental waveforms of the active power and the FFT results with/without the proposed algorithm. Before compensation, the active power has the one and two times ripple components as shown in Fig. 14. However, after compensation of the offset errors, the one time ripple of the fundamental slip is considerably reduced as shown in Fig. 15. In addition, the two times ripple component

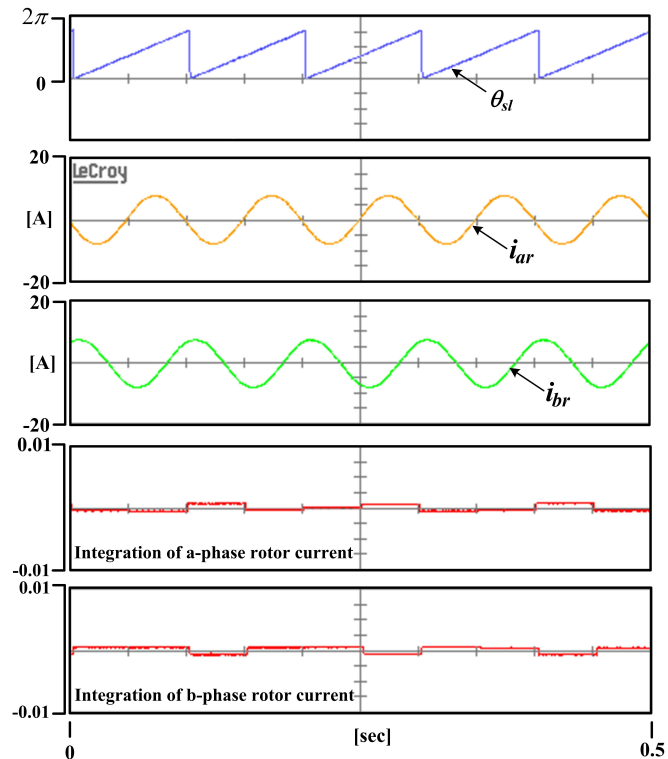

Fig. 12. Compensation value of offset errors in sector (a).

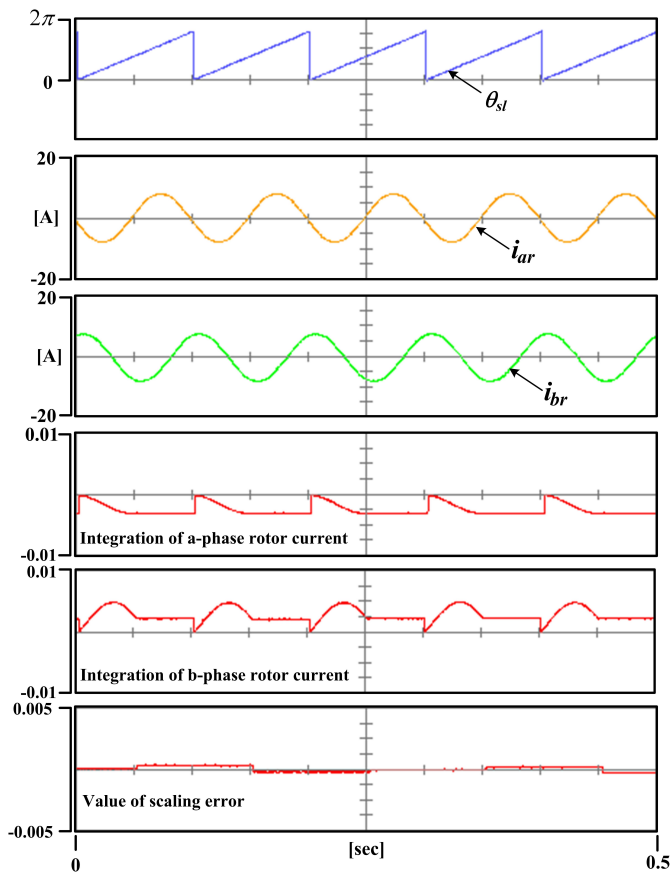

Fig. 13. Compensation values of scaling error in sector (b).

caused by the scaling error is also decreased by the proposed algorithm as shown in Fig. 16.

\section{CONCLUSIONS}

This paper analyzes the effects of current measurement errors in a doubly fed induction generator. The $d q$-axis current ripples are caused by the offset and scaling errors in the current measurement path. As a result, ripples of the active and reactive powers can be generated due to the current measurement errors. The proposed compensation algorithm was presented to compensate for the offset and scaling errors by integrating 3-phase rotor currents into the stationary reference frame. Therefore, this algorithm has the following attractive features: 


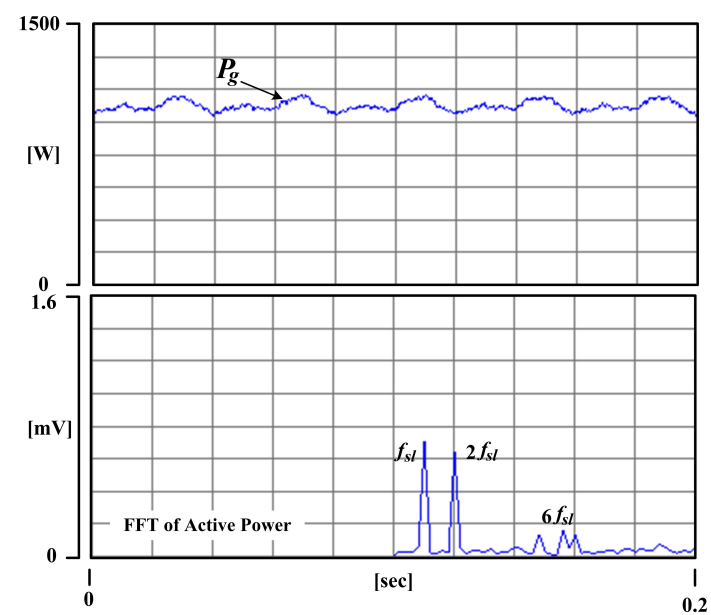

Fig. 14. Experimental waveforms of active power and FFT result, before compensation of the offset and scaling errors.

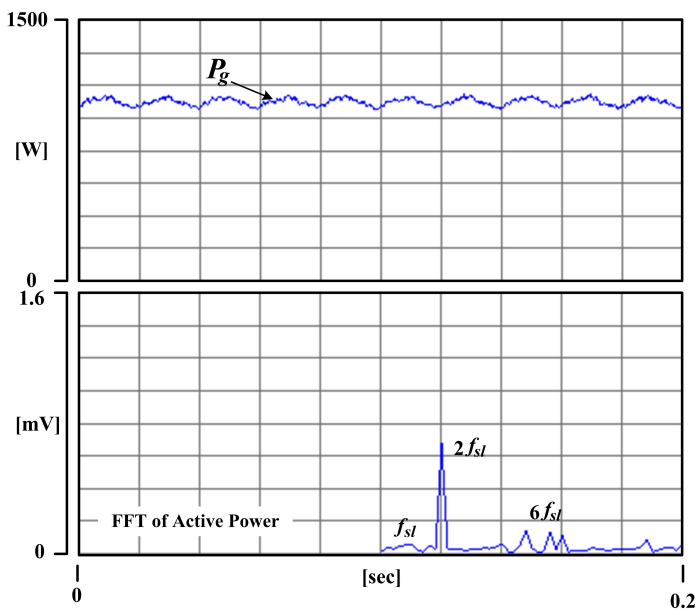

Fig. 15. Experimental waveforms of active power and FFT result, after compensation of the offset errors.

easy implementation, less computation time, and robustness with respect to variations in the electrical parameters because electrical parameters are not needed to implement the proposed method. The experimental results verify the effectiveness of the proposed compensation method.

\section{APPENDIX}

TABLE I

PARAMETERS OF DFIG

\begin{tabular}{|l|l|l|l|}
\hline Rated power & $2.2 \mathrm{~kW}$ & $\mathrm{Rr}$ & $0.5855 \Omega$ \\
Rated speed & $1800 \mathrm{rpm}$ & $\mathrm{Ls}$ & $84.4 \mathrm{mH}$ \\
Pole pairs & 3 & $\mathrm{Lr}$ & $84.4 \mathrm{mH}$ \\
Rs & $0.5855 \Omega$ & $\mathrm{Lm}$ & $74.7 \mathrm{mH}$ \\
\hline
\end{tabular}

\section{ACKNOWLEDGMENT}

This work has been supported by KETEP (Korea Institute of Energy Technology Evaluation and Planning) (20091020300380-11-2-100), which is funded by MKE (Ministry of Knowledge Economy).

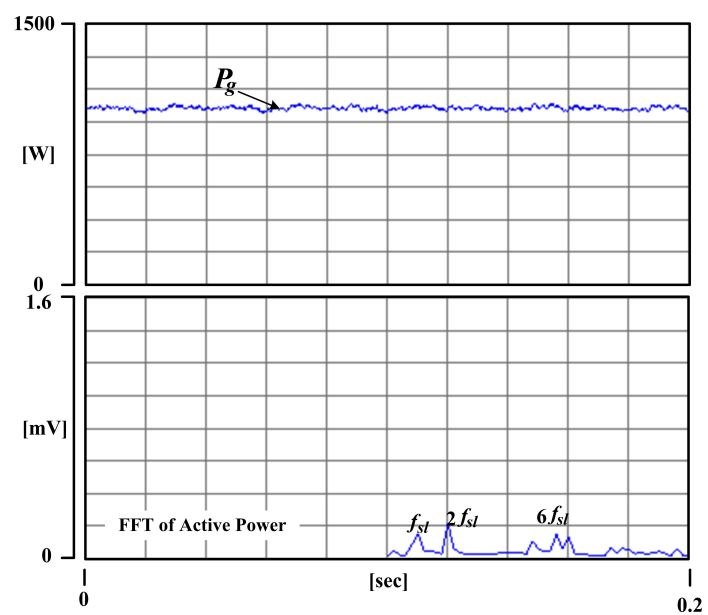

Fig. 16. Experimental waveforms of active power and FFT result, after compensation of the offset and scaling errors.

\section{REFERENCES}

[1] S. Muller, M. Deicke, and R. W.De Doncker, "Doubly fed induction generator systems for wind turbines," IEEE Ind. Applicat. Mag., pp. 26-33, May/Jun. 2002.

[2] N. Jenkins, J. B. Ekanayake, L. Holdsworth, and X. Wu, "Dynamic modeling of doubly fed induction generator wind turbines," IEEE Trans. Power Syst., Vol. 18, Issue 2, pp. 803-809, May 2003.

[3] R. Pena, J. C. Clare, and G. M. Asher, "Doubly fed induction generator using back-to-back PWM converters and its application to variable-speed wind-energy generation," Proc. Inst. Elect. Eng., Elect. Power Applicat., Vol. 143, No. 3, May 1996.

[4] J. B. Ekanayake, L. Holdsworth, and N. Jenkins, "Control of doubly fed induction generator (DFIG) wind turbine," Proc. Inst. Elect. Eng., Power Eng., Vol. 17, No. 1, pp. 28-32, Feb. 2003.

[5] M. Yamamoto and O. Motoyoshi, "Active and reactive power control for doubly-fed wound rotor induction generator," IEEE Trans. Power Electron., Vol. 6, No. 4, pp. 624-629, Oct. 1991.

[6] B. Hopfensperger, D. J. Atkinson, and R. A. Lakin, "Stator-flux-oriented control of a doubly-fed induction machine with and without position encoder," Proc. Inst. Elect. Eng., Electr. Power Appl., Vol. 147, No. 4, pp. 241-250, Jul. 2000.

[7] S. D. Rubira and M. D. McCulloch, "Control method comparison of doubly fed wind generators connected to the grid by asymmetric transmission lines," IEEE Trans. Ind. Applicat., Vol. 36, No. 4, pp. 986991, Jul./Aug. 2000.

[8] Y. Hu, M. Cirstea, M. McCormick, P. Urwin, and L. Haydock, "Modeling and simulation of a variable speed stand-alone generator system," in Proc. Inst. Elect. Eng. Int. Conf. Power Electron. Variable Speed Drives London, U.K., pp. 372-377, 2000.

[9] Z. M. Salameh and L. F. Kazda, "Analysis of the double output induction generator using direct three-phase model, part II—harmonic analysis," IEEE Trans. Energy Conversion, Vol. 2, Issue 2, pp. 182-188, Jun. 1987.

[10] Y. Liao, D. Xiang, L. Ran, and G. A. Putrus, "Harmonic transfer in an a.c. excited generator including speed ripple," in Proc. 28th Annu. Conf. IEEE Ind. Electron. Soc. Sevilla, Spain, 2002.

[11] Y. Liao, D. Xiang, L. Ran, and G. A. Putrus, "Evaluation of the Effects of Rotor Harmonic transfer in an a.c. excited generator including speed ripple," in Proc. 28th Annu. Conf. IEEE Ind. Electron. Soc. Sevilla, Spain, 2002.

[12] H. S. Jung, S. H. Hwang, J. M. Kim, C. U. Kim and C. Choi, "Diminution of Current-Measurement Error for Vector-Controlled AC Motor Drives," IEEE Trans. Ind. Applicat., Vol. 42, No. 5, pp. $1249-$ 1256, Sep./Oct. 2006.

[13] D. W. Chung and S. K. Sul, "Analysis and compensation of current measurement error in vector-controlled AC motor drives," IEEE Trans. Ind. Applicat., Vol. 34, No. 2, pp. 340-345, Mar,/Apr, 1998.

[14] J. -W. Choi and S.-K.Sul, "Inverter output voltage synthesis using novel dead time compensation," IEEE Trans. Power Electron., Vol.11, No.2, pp.221-227, Mar. 1996.

[15] A. R. Munoz and T. A. Lipo, "On-line dead-time compensation technique for open-loop PWM-VSI drives," IEEE Trans. Power Electron., Vol. 14, No. 4, pp.683-689, Jul. 1999. 


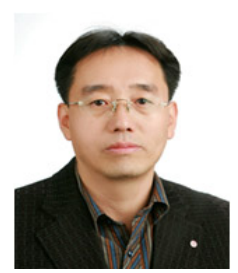

Gwi-Geun Park was born in Chungnam, Korea, in 1965. He received his B.S. in Electronics Engineering from Kyungnam University, Kyungnam, Korea, in 1990 and his M.S. in 2006, from the Department of Intelligent Machinery System, Pusan National University, Busan, Korea, where he is currently working toward his Ph.D. Since 1990, he has been working as a Chief Research Engineer at LG Electronics Inc. His current research interests include motor drives and the control of electrical machines, power converters, and inverter air conditioners.

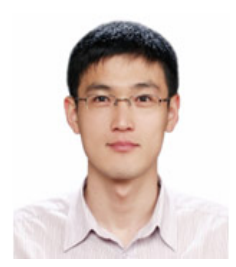

Seon-Hwan Hwang was born in Chungnam, Korea, in 1978. He received his B.S. and M.S. in Electrical Engineering from Pusan National University, Busan, Korea, in 2004 and 2006, respectively. He is currently working toward his Ph.D. at Pusan National University. His research interests include power conversion and electric machine drives.

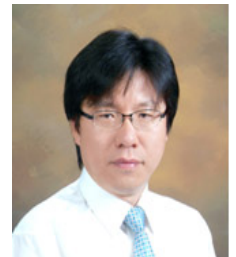

Jang-Mok Kim was born in Busan, Korea, in August 1961. He received his B.S. from Pusan National University in 1988, and his M.S. and Ph.D. from Seoul National University, Korea, in 1991 and 1996, respectively, in the department of Electrical Engineering. From 1997 to 2000, he was a Senior Research Engineer with the Korea Electrical Power Research Institute (KEPRI). Since 2001, he has been with the School of Electrical Engineering, Pusan National University (PNU), where he is currently a faculty member. In addition, he is a Research Member of the Research Institute of Computer Information and Communication at PNU. His present interests include the control of electric machines, electric vehicle propulsion, and power quality.

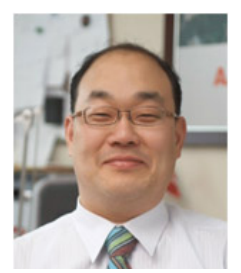

Kyo-Beum Lee was born in Seoul, Korea, in 1972. He received his B.S. and M.S. in Electrical and Electronic Engineering from Ajou University, Korea, in 1997 and 1999, respectively. He received his Ph.D. in Electrical Engineering from Korea University, Korea in 2003. From 2003 to 2006, he was with the Institute of Energy Technology, Aalborg University, Aalborg, Denmark. From 2006 to 2007, he was with the Division of Electronics and Information Engineering, Chonbuk National University, Jeonju, Korea. Since 2007, he has been with the Division of Electrical and Computer Engineering as an Associate Professor at Ajou University. $\mathrm{He}$ is an Associate Editor of the IEEE Transactions on Power Electronics and the Journal of Power Electronics. His research interests include electric machine drives and wind power generations.

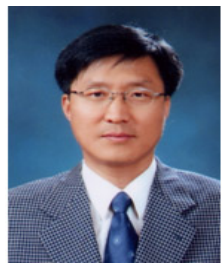

Dong-Choon Lee received his B.S., M.S., and Ph.D. in Electrical Engineering from Seoul National University, Seoul, Korea, in 1985, 1987, and 1993, respectively. He was a Research Engineer with Daewoo Heavy Industry from 1987 to 1988 . Since 1994, he has been a faculty member with the Dept. of Electrical Engineering, Yeungnam University, Gyeongbuk, Korea. Currently, he is a Full Professor and a Vice Dean of Academic Affairs, College of Engineering. In addition, he is serving as a Publication Editor, Journal of Power Electronics, Korean Institute of Power Electronics, Korea. As a Visiting Scholar, he joined the Power Quality Laboratory, Texas A\&M University, College Station in 1998, the Electrical Drive Center, University of Nottingham, U.K. in 2001, and the Wisconsin Electric Machines \& Power Electronic Consortium, University of Wisconsin, Madison in 2004. His research interests include ac machine drives, control of power converters, wind power generation, and power quality. 